\title{
“QUANDO ELES CRESCEM, ELES VOAM": PERCEPÇÕES E SENTIMENTOS MATERNOS FRENTE AO DESENVOLVIMENTO INFANTIL AOS 18 - 20 MESES
}

\author{
Rita de Cássia Sobreira Lopes \\ Aline Groff Vivian ${ }^{\#}$ \\ Débora S. de Oliveira\# \\ Carla da Silva \\ Cesar Augusto Piccinini \\ Jonathan Tudge
}

\begin{abstract}
RESUMO. O presente estudo visou investigar as percepções e sentimentos maternos diante das aquisições de desenvolvimento da criança dos 18 aos 20 meses. Participaram 14 mães primíparas, com idades entre 20 e 37 anos, de níveis socioeconômicos variados, residentes com o marido na região metropolitana de Porto Alegre. Foi realizada e submetida à análise qualitativa de conteúdo uma entrevista semiestruturada que abordava a experiência da maternidade e o desenvolvimento da criança. Buscou-se examinar semelhanças e particularidades das percepções e sentimentos maternos ante as aquisições de desenvolvimento infantil. Os resultados revelaram um incremento nas aquisições de linguagem, motoras, socioemocionais e intelectual-cognitivas. As crianças demandaram maior atenção e disponibilidade materna, acarretando nas mães sentimentos positivos, negativos e ambivalentes. É importante que a mãe compreenda as aquisições próprias desse período, pois isso contribuirá para que ela lide mais adequadamente com uma relação que oscila entre dependência e independência.
\end{abstract}

Palavras-chave: Percepções maternas; sentimentos maternos; desenvolvimento infantil.

\section{“WHEN THEY GROW, THEY FLY”: MATERNAL FEELINGS AND PERCEPTIONS CONCERNING CHILD DEVELOPMENT AT 18 - 20 MONTHS}

\begin{abstract}
The present study aimed to investigate maternal perceptions and feelings concerning child's developmental acquisitions from 18 to 20 months. Fourteen primiparus mothers, aged 20 to 37, of different socioeconomic background took part in the study. They lived with their partners in the metropolitan region of Porto Alegre. A semi-structured interview was carried out, which was analyzed according to content analysis. The analysis focused on maternal experience and child development. The similarities and particularities of maternal perception and feelings concerning developmental acquisitions were examined. Results revealed an increase in language, motor, socio-emotional and cognitive-intellectual acquisitions. Children demanded more maternal attention and availability, provoking positive, negative and ambivalent feelings from their mother. It is important that mothers understand the acquisitions from this period which will enable them to deal more adequately with a relationship that oscillates between dependence and independence.
\end{abstract}

Key words: Maternal perception; maternal feelings;, child development.

* Doutor(a). Pesquisador(a) do CNPq e docente do PPG Psicologia da Universidade Federal do Rio Grande do Sul (UFRGS).

\# Psicóloga. Doutoranda no PPG-Psicologia da UFRGS.

II Bolsista de iniciação científica do CNPq, discente do Curso de Psicologia da UFRGS.

æ Doutor. Professor of Department of Human Development and Family Studies of University of North Carolina at Greensboro e professor colaborador do PPG-Psicologia da UFRGS. 


\title{
“CUÁNDO LOS NIÑOS CRECEN, LOS NIÑOS VUELAN": PERCEPCIONES MATERNALES Y LOS SENTIMIENTOS DELANTE DE LAS ADQUISICIONES DEL DESARROLLO A LOS 18 - 20 MESES
}

\begin{abstract}
RESUMEN. Este estudio tuvo como objetivo investigar las percepciones maternales y los sentimientos delante de las adquisiciones del desarrollo del niño de los 18 a los 20 meses. Participaron 14 madres primíparas, con edades entre 20 y 37 años, con nivel socioeconómico variado y que conviven con sus respectivos maridos en la región metropolitana de Porto Alegre. Fue realizada una entrevista semi-estructurada, submetida al análisis cualitativo del contenido, que abordó la experiencia de la maternidad y el desarrollo del niño. Se buscó examinar semejanzas y particularidades de las opiniones y sentimientos maternales frente a las adquisiciones del desarrollo infantil. Los resultados indicaron adquisiciones intensas de la lengua, de la motricidad, socio-emocionales y intelectuales-cognitivas. Los niños exigieron mayor atención y disponibilidad de las madres, causando sensaciones positivas, negativas y ambivalentes en las mismas. Es importante que la madre entienda las adquisiciones apropiadas de este período ya que contribuirá para un trato más adecuado en una relación que oscila entre la dependencia y la independencia del niño.
\end{abstract}

Palabras-clave: Percepciones maternales; sentimientos maternos; desarrollo infantil..

O segundo ano de vida se caracteriza como um momento importante do desenvolvimento infantil, sendo particularmente estudado o segundo semestre, a partir dos 18 meses (Mahler, 1982; Pine, 2004). Nesse período, há um rápido incremento das aquisições de linguagem e motricidade, além de novas habilidades intelectuais, cognitivas e socioemocionais (Colson \& Dworkin, 1997). A linguagem é uma aquisição que se complexifica ao longo do segundo ano, constituindo-se em um dos avanços mais significativos (Colson \& Dworkin, 1997). Aos 18 meses as crianças estão aprendendo a falar palavras que se referem a objetos, pessoas e ações familiares (Hodges, Vigil \& Klee, 2005) e já começam a falar sobre suas emoções (Shaffer, 2005).

Além da linguagem, a criança apresenta importantes aquisições em termos de motricidade. Está aprendendo a andar, cai e tropeça em objetos parados quando tenta chegar rapidamente a algum lugar (Shaffer, 2005). Estas aquisições, de forma variável, a partir do final do primeiro ano, possuem grande impacto no desenvolvimento psicológico e físico da criança (Steiner, 1999). Permitem também à criança apresentar uma maior capacidade para realizar movimentos de afastamento e de reaproximação de seus cuidadores (Brazelton, 2002; Mahler, 1982; Newcombe, 1999). Esta reaproximação inicia quando a criança já é capaz de caminhar livremente, o que costuma ocorrer por volta dos 14 aos 22 meses (Mahler, 1982). Para Mahler (1982), a criança percebe que seus objetos de amor são indivíduos separados, com seus próprios desejos, na medida em que compreende que é possível separar-se fisicamente da mãe quando quiser. Ao experienciar situações em que haja uma atuação independente, o bebê vivencia tanto sentimentos de prazer quanto de ansiedade. $\mathrm{O}$ relativo esquecimento da mãe, característico desse período, passa a ser alterado pela preocupação com uma aproximação da mãe nos momentos de exploração (Mahler, 1982).

Em termos da busca de independência, também é comum ver crianças de dois anos explorando todas as variações possíveis de comportamentos aceitáveis na presença de pais e irmãos (Newcombe, 1999). A criança tem maior autonomia para se locomover fisicamente e, psicologicamente, está explorando a ideia de estar mais separada de sua mãe e encontra-se mais apta a efetivar esta separação (Miller, 1999). O incremento na independência costuma estar acompanhado de um senso de confiança em si mesma e também de limitações. A criança pode apresentar ambivalência quanto à aquisição de independência e oscilar em termos de suas expressões de autonomia e separação (Miller, 1999).

Nos momentos de brincadeira, durante o segundo ano, a criança consegue expressar seus sentimentos e experiências, uma vez que começa a aprender a lidar com o mundo externo (Mendes \& Moura, 2004; Steiner, 1999). Ela também dimensiona em alguma medida seus próprios recursos. Isso ocorre através da manipulação, exploração e possibilidade de simbolizar através dos brinquedos e dos objetos (Steiner, 1999). Outra importante função da brincadeira é ajudar a criança a lidar com emoções como amor, ódio, ansiedade e agressão. Também através do brincar, criança e mãe interagem de forma a promover o desenvolvimento emocional e as capacidades sociocognitivas infantis (Mendes \& Moura, 2004).

No que se refere ao desenvolvimento intelectualcognitivo, do primeiro ao terceiro ano a criança adquire a capacidade de imitação seletiva ou de repetir ações específicas observadas em outras pessoas (Moura \& Ribas, 2002). A imitação é uma forma de aprender e aperfeiçoar novas ações e está relacionada à habilidade 
simbólica (Sohr-Preston \& Scaramella, 2006). O crescimento dessa capacidade e da autoconsciência tornase um progresso importante (Thompson \& Lagattuta, 2005).

Não obstante, para muitos pais e outras pessoas que lidam com crianças pequenas, as mudanças nestes anos podem ser difíceis de manejar (Newcombe, 1999). Ajustes emocionais serão realizados não apenas na criança, mas também na mãe, que tem que lidar com a perda de uma relação de maior dependência da criança em relação a ela e se adaptar a um filho mais autônomo (Miller, 1999). As mudanças ocorrentes nessa faixa etária têm repercussões nos sentimentos maternos, já que o filho costuma apresentar novos comportamentos e capacidades que podem se constituir como um desafio para a mãe, a qual tem que aprender a lidar com as implicações destas aquisições (Shaffer, 2005). Este período muitas vezes é chamado, coloquialmente, de "os terríveis dois anos". Os desejos das crianças e dos adultos também podem ser confrontados através da agressividade, padrões de higiene, horários de sono e outros aspectos cotidianos (Newcombe, 1999).

Todos estes aspectos ligados ao desenvolvimento infantil significam muito para a mãe, devido aos intensos sentimentos envolvidos. Lopes et al. (2007) realizaram um estudo envolvendo 28 mães de bebês com 12 meses de idade, as quais foram entrevistadas a respeito do desenvolvimento infantil. Os resultados mostraram que aos 12 meses a criança apresenta novas aquisições de linguagem, locomoção e exploração, o que a permite realizar movimentos de afastamento e reaproximação do cuidador. Nesse momento, a mãe ocupa papel fundamental, pois deve proporcionar oportunidades para descobertas e favorecer explorações. A criança costuma alterar seus comportamentos de maior passividade para maior atividade, desencadeando nas mães sentimentos ambivalentes, positivos e negativos.

Embora algumas aquisições de desenvolvimento já estejam presentes aos 12 meses, despertando intensos sentimentos maternos, conforme apontado por Lopes et al. (2007), no final do segundo ano de vida há um incremento de aquisições de linguagem, motoras, socioemocionais e intelectual-cognitivas. Há, também, uma maior oscilação de comportamento entre independência e dependência (Steiner, 1999). As mães costumam apresentar diferentes reações e sentimentos diante dessas iniciativas de seu filho. Essas mudanças e o modo como a criança e a família lidam podem vir a configurar seus relacionamentos com o mundo externo.

Tendo-se em vista que as aquisições de desenvolvimento da criança ao longo do segundo ano de vida são rápidas e significativas e estão associadas frequentemente a regressões de comportamentos anteriormente adquiridos, torna-se importante atentar, em especial, para as repercussões emocionais que este período do desenvolvimento desencadeia nas mães. Em pesquisa realizada em bases de dados (PsychInfo, Scielo, BVS-Psi, EBSCOhost e Lilacs) foram encontrados estudos empíricos, alguns deles destacados acima, que investigaram o desenvolvimento infantil dos 18 aos 20 meses, porém não foram encontrados artigos que tivessem examinado especificamente as percepções e sentimentos maternos diante das aquisições deste período. A partir do exposto, o presente estudo investigou as percepções e os sentimentos das mães em face das aquisições de desenvolvimento infantil, dos 18 aos 20 meses.

\section{MÉTODO}

\section{Participantes}

Participaram deste estudo 14 mães, com idades entre 20 e 31 anos, as quais tinham um único filho ${ }^{1}$ (6 meninos e 8 meninas), com idades entre 18 e 20 meses. As famílias, que em todos os casos incluíam o pai da criança, eram de diferentes níveis socioeconômicos e residiam na região metropolitana de Porto Alegre. Em termos de status ocupacional da família, duas mães não trabalhavam fora do lar e as demais tinham profissões variadas, classificadas como de baixo status (2), médio (3) e alto status (4), de acordo com Hollingshead (Hollingshead, 1975; Tudge \& Frizzo, 2002). A Tabela 1 apresenta as características sociodemográficas das participantes.

Tabela 1. Características Sóciodemográficas das participantes

\begin{tabular}{lllllll}
\hline Mãe & \multicolumn{3}{l}{ Idade Escolaridade } & Ocupação & $\begin{array}{c}\text { NSE Sexo da Idade } \\
\text { criança } \\
\text { criança }\end{array}$ \\
\hline M1 & 24 & Fund. Comp & Doméstica & 1 & Fem & $18 \mathrm{~m}$ \\
M2 & 23 & Fund. Inc & Doceira & 2 & Mas & $20 \mathrm{~m}$ \\
M3 & 30 & Sup. Comp & Aux. de Laboratório & 4 & Fem & $19 \mathrm{~m}$ \\
M4 & 24 & Fund. Inc & Auxiliar Escritório & 2 & Fem & $19 \mathrm{~m}$ \\
M5 & 26 & Fund. Inc & Dona de Casa & 1 & Mas & $18 \mathrm{~m}$ \\
M6 & 29 & Méd. Comp & Técn. Enfermagem & 3 & Fem & $18 \mathrm{~m}$ \\
M7 & 27 & Méd. Comp & Serviços Gerais & 1 & Mas & $18 \mathrm{~m}$ \\
M8 & 23 & Méd. Comp & Recepcionista & 3 & Mas & $18 \mathrm{~m}$ \\
M9 & 27 & Sup. Inc & Técn. Enfermagem & 4 & Fem & $18 \mathrm{~m}$ \\
M10 & 25 & Sup. Inc & Dona de Casa & 4 & Mas & $19 \mathrm{~m}$ \\
M11 & 31 & Sup. Inc & Professora de Yoga & 4 & Mas & $18 \mathrm{~m}$ \\
M12 & 24 & Sup. Inc & Digitadora/Garçonet & 3 & Fem & $20 \mathrm{~m}$ \\
M13 & 20 & Méd. Comp & Telefonista & 3 & Fem & $19 \mathrm{~m}$ \\
M14 & 30 & Sup. Comp & Inspetora de Polícia & 4 & Fem & $19 \mathrm{~m}$ \\
\hline
\end{tabular}

1 Este termo será usado neste artigo como sinônimo para menino e menina. 
A amostra foi selecionada, com base nos critérios descritos acima, dentre os participantes do "Estudo Longitudinal de Porto Alegre: Da Gestação à Escola” - ELPA (Piccinini, Tudge, Lopes \& Sperb, 1998), que teve por objetivo investigar diversos aspectos subjetivos e comportamentais das interações iniciais pai-mãe-bebê, bem como o impacto de fatores iniciais do desenvolvimento nas interações familiares, no comportamento social de crianças pré-escolares e na transição para a escola de ensino fundamental. $\mathrm{O}$ estudo iniciou acompanhando 81 gestantes que não apresentavam intercorrências clínicas, seja com elas mesmas seja com o bebê, que era seu primeiro filho. Os participantes representavam várias configurações familiares (nucleares, monoparentais ou recasados), de diferentes idades (adultos e adolescentes) e com graus de escolaridade e níveis socioeconômicos variados. Como parte do ELPA foram realizadas coletas de dados desde a gestação até os sete anos das crianças. Para fins do presente artigo, foram incluídos todos os casos que atendiam aos critérios descritos acima e tinham dados completos da criança referentes à sua idade dos 18 aos 20 meses. O ELPA foi aprovado pelo Comitê de Ética da UFRGS (Resolução n. ${ }^{\circ}$ 98293) e os participantes assinaram o Termo de Consentimento Livre $e$ Esclarecido. Além dos dados sociodemográficos coletados na gestação, o presente estudo considerou dados obtidos quando a criança estava com idade entre dezoito e vinte meses completos.

\section{Procedimentos e Instrumentos}

As percepções e os sentimentos maternos em face do desenvolvimento da criança foram investigados através de uma entrevista respondida pela mãe quando a criança estava com 18 a 20 meses. As famílias, que já vinham sendo acompanhadas desde a gestação do filho, como parte do ELPA, foram novamente contatadas nesse período, quando se agendava um novo encontro no Instituto de Psicologia da UFRGS. Nesta ocasião, a mãe respondia à Entrevista sobre a Experiência da Maternidade e o Desenvolvimento do Bebê aos Dezoito Meses (GIDEP, 1998), além de outros instrumentos descritos em Piccinini et al. (1998), cujos dados não foram incluídos no presente artigo. Esta entrevista estruturada era composta de diversos temas relacionados ao desenvolvimento infantil, à experiência da maternidade e às percepções maternas sobre os cuidados paternos para com a criança e sobre a participação de outros cuidadores e da creche. A entrevista foi realizada de forma semidirigida e o entrevistador foi orientado a explorar as respostas maternas. Para fins de análise do presente estudo, foram particularmente examinadas as seguintes questões: Como está o desenvolvimento do (nome)? O que ele é capaz de fazer que te chama mais a atenção? Ele já está falando? Quando foi o início? Como foi? Como tu descreverias o jeito do teu bebê? Como tu estás te sentindo como mãe neste momento? Quais foram os momentos em que vocês tiveram que ficar longe? Como te sentiste? Caso o conteúdo investigado aparecesse em outros momentos da entrevista, era também considerado para fins de análise.

Além da entrevista com a mãe foram considerados para análise dados oriundos da Ficha de Contato Inicial (GIDEP, 1998), que buscava investigar se a mãe e a família se adequavam aos critérios de inclusão, e da Entrevista de Dados Demográficos (GIDEP, 1998), cujos dados permitiram caracterizar a escolaridade e o nível socioeconômico das participantes. Ambos os instrumentos foram respondidos pela mãe ainda na gestação.

\section{RESULTADOS}

Foi realizada uma análise qualitativa de conteúdo (Bardin, 1977; Laville \& Dione, 1999) para examinar as percepções e os sentimentos das mães quanto ao desenvolvimento do filho ${ }^{1}$ que tinha entre 18 e 20 meses, em particular quanto às suas novas aquisições nesse período. Para fins de análise, foram criadas, com base na literatura (Brazelton, 2002; Colson \& Dworkin, 1997; Newcombe, 1999; Papalia, Olds \& Feldman, 2006; Shaffer, 2005), quatro categorias, que refletiam as principais aquisições de desenvolvimento da criança nessa idade: 1) de linguagem; 2) motoras; 3) socioemocionais; e 4) intelectual-cognitivas. Os sentimentos maternos em relação às novas aquisições foram classificados como positivos, negativos ou ambivalentes (Lopes et al., 2007). Após leituras exaustivas das entrevistas, duas autoras do presente estudo classificaram separadamente os relatos das mães em cada categoria, e, em caso de discordância, utilizou-se um terceiro juiz. A seguir, serão apresentadas e discutidas as categorias, buscando-se exemplificá-las através das verbalizações das mães.

\section{Aquisições de linguagem}

Esta primeira categoria temática refere-se às percepções e sentimentos maternos quanto à aquisição

1 A expressão filho será utilizada neste trabalho para designar tanto o sexo feminino quanto o masculino. 
da linguagem do filho. Algumas mães (5) ${ }^{2}$ destacaram a habilidade de comunicação e expressão dos filhos: "Ela é uma tagarela, não para um minuto, é uma papagaia" (M4; 19m) $)^{3}$; "Ela é bem espontânea $e$ expressiva, fica fácil” (M6; 18m). Em contraposição, houve mães (3) que descreveram seus filhos como preguiçosos, ao caracterizarem o início da aquisição de linguagem: "Ele é muito preguiçoso para falar, bico ele está dizendo que é cal, aí eu já sei que é bico, só que eu estou puxando para ele falar bico" (M8; $18 \mathrm{~m})$; "Eu acho ela preguiçosa para falar" (M14; $19 \mathrm{~m})$. Para surpresa de uma das mães, seu filho apresentava um ritmo próprio de linguagem: "Ela já está começando, às vezes sai com umas coisas que até tu não acredita muito, a gente não espera, tudo que ela ouve ela repete, devagar, do jeito dela" (M3; $19 \mathrm{~m})$. Esta aquisição de linguagem também foi associada à repetição de palavras, por algumas mães (3): “Está uma explosão de coisas novas que ela fala... Ela repete muito o que a gente fala. Tu usa uma expressão nova e em seguida ela já usa” (M9; 18m). $\mathrm{O}$ uso de palavras e frases curtas pelas crianças foi apontado por muitas mães (11) como algo que favoreceu a comunicação da dupla: "Mas ela é trifalante, ela conversa contigo, pede as coisas. Se ela não gosta, ela diz que não quer" (M13; 20m); "Ele não fala bem certo as palavras, mas dá para entender o que ele está querendo falar” (M5; 18m); “Eu acho que a comunicação dela está boa, a gente consegue se comunicar direitinho" (M6; 18m).

Além do uso da linguagem verbal, várias mães (6) também destacaram que as crianças apontavam para objetos do cotidiano e procuravam se comunicar através de gestos e linguagem não-verbal, manifestando suas preferências e facilitando a comunicação com a mãe: "Mas ele mais aponta, puxa, bate quando ele quer alguma coisa, mais do que falar" (M10; 19m); “Através do olhar, das mãos, da maneira impressionante como ele se comunica, a facilidade que ele tem... tu consegue entender tudo" (M11; 18m). Contudo, duas mães perceberam que ao atenderem aos gestos dos filhos poderiam estar substituindo o uso da linguagem verbal: "Eu observei que para ele não ter que falar, ele fica me mostrando, me chama, e antes, tudo que queria ele ficava tentando falar e eu já ia lá e alcançava. Aí eu observei isso e estou mudando. Eu deixo ele insistir, para ver se consegue falar" (M5; 18m); "Agora ela aponta

2 O número entre parênteses indica a quantidade de mães que referiram a aquisição mencionada.

3 A letra $\mathrm{M}$ acompanhada do número identifica cada mãe participante, seguida da idade do bebê, cfe. Tabela 1. bastante, aí eu procuro dizer para ela o nome daquilo. Só que ela não fala o nome, só quando tem vontade" (M14; $19 \mathrm{~m})$.

No que se refere aos sentimentos relativos à aquisição de linguagem a maioria das mães (11) relatou sentimentos positivos, como felicidade, satisfação e admiração por a criança estar se comunicando: "Eu acho lindo, eu fico toda boba. Eu adoro ficar vendo ele com essas mudanças" (M5; 18m); "Ela está falando um monte de coisas, tem coisa que ela fala que eu fico de boca aberta, não sei da onde que ela tira” (M4; 19m). Duas mães também mencionaram sentimentos positivos ante as aquisições de linguagem, as quais acabaram favorecendo a interação mãe-criança e a compreensão materna: "Acho lindo, várias coisas que ela fala. Cada dia que passa ela aprende a falar melhor as palavras, fico toda emocionada. Acho que é mais fácil lidar com ela à medida que ela vai crescendo, é melhor porque eu consigo entender o que ela está falando e eu consigo falar com ela e ela me responder" (M12; 21m); "Eu adoro quando ela diz: 'Mamãe!' e vem correndo e me abraça, faz carinho. Conversa comigo, isso é super bom" (M3; 19m). Nenhum dos relatos maternos envolveu sentimentos maternos negativos ou ambivalentes.

\section{Aquisições motoras}

Esta categoria diz respeito às percepções e sentimentos maternos quanto às aquisições motoras da criança. Os relatos foram classificados em duas subcategorias: fina e ampla. Quanto à motricidade fina, foram consideradas as habilidades mais específicas como rabiscar, desenhar formas simples, segurar e manipular objetos. Algumas mães (3) mencionaram que as crianças já desenhavam ou rabiscavam e apreciavam esta atividade, que repercutia na interação mãe-criança: "Ela gosta de escrever, desenhar. Ela pede: 'Ó, mamãe, desenha um avião, desenha um coração, desenha a maçã ", (M9; 18m). Algumas mães (3) destacaram que a criança segurava e manipulava objetos como forma de manifestar interesse e curiosidade: "Ela curte tudo, curte os brinquedos dela, mexer nas coisas, porque é muito curiosa, muito interessada" (M13; 20m). A motricidade da criança também foi entendida por uma das mães como uma maneira de explorar e conhecer o ambiente e de reconhecer pessoas: "Ele gosta é de ficar na sala, despejar todos os brinquedos, brincar e depois botar na caixa de volta; gosta de mexer em tudo, abre gaveta. Ele gosta muito de olhar fotografia, reconhece o pai e a mãe na fotografia” (M5; 18m). 
A motricidade ampla refere-se às percepções maternas quanto às atividades da criança como caminhar e correr, ou movimentar-se ativamente. Uma maior agilidade da criança foi relatada por duas mães como sendo prazerosa para os filhos, uma vez que através dela acabavam demonstrando suas preferências: "Ele gosta de estar se movimentando, não gosta de ficar sentado muito tempo num lugar só" (M2; 20m); "Ela gosta de dançar, onde tem música está pulando e dançando" (M3; 19m). Essas mudanças decorrentes de uma maior habilidade motora da criança possibilitaram sua postura mais ativa, o que foi destacado por algumas mães (5): "Mudou bastante coisa, depois que começou a caminhar, está mais mexerico, mexe em tudo" (M5; $18 \mathrm{~m})$; "Ele não pode ficar subindo e quer subir [na mesa] e quer ficar em cima da cadeira e bagunça tudo. Porque ele não fica paradinho, sentadinho" (M10; 19m). Houve também referência, por parte de algumas mães (3), de que a criança parecia demonstrar maior segurança e capacidade de explorar o ambiente: "Ele é superseguro, sobe na escada, tranquilo" (M8; $18 \mathrm{~m})$; "Ele quer ficar subindo e descendo [as escadas] toda hora, ele acha novidade" (M7; 18m). Esta maior atividade também pareceu demandar maior cuidado e atenção por parte de uma das mães: "Ele superativo, ligeirinho, tem que estar cuidando, porque em minutinhos está fazendo arte" (M8, 18m).

No que se refere aos sentimentos ambivalentes diante das aquisições motoras, uma mãe relatou que, por um lado havia o desconforto, pelo fato de a criança estar exigindo maior atenção, em decorrência do incremento de suas habilidades motoras e de exploração do ambiente; por outro não havia incômodo, em função de a mãe compreender que tais atitudes são próprias do desenvolvimento: "É chato, porque às vezes tu tá fazendo outra coisa ou tá apressada, tem que trabalhar, aí incomoda. Quando a gente está light em casa eu não me incomodo muito, porque eu sei que é normal aquilo na criança, aos poucos ela vai entendendo tudo" (M14; $19 \mathrm{~m})$.

\section{Aquisições socioemocionais}

Esta terceira categoria diz respeito às percepções e sentimentos maternos decorrentes das aquisições socioemocionais do filho, com destaque para a aquisição da independência da criança. Várias mães (6) destacaram que a criança passou a demonstrar de maneira mais clara suas preferências, já apresentando opinião própria e expressando seus sentimentos: "Se ela quer aquilo, tem que ser aquilo, senão tu não aguenta a choradeira, ela fica braba, destrata, xinga. Ela tem opinião própria” (M4;19m); "Ele consegue expressar mais as coisas, o que ele quer ou o que está sentindo ou se está brabo, ele se irrita e briga, mostra que está brabo, se ele está feliz ele mostra que está feliz. Então, ele sabe agora diferenciar, tudo direitinho" (M8; $18 \mathrm{~m})$; "Até poucos dias ela dava tudo, cedia tudo, brincava (...) agora ela já tira as coisas e diz que é dela - 'é meu'.” (M6; 18m).

Algumas mães (5) fizeram associação entre os comportamentos da criança de manifestar seus desejos e opiniões próprias e o processo de crescimento do filho: "Ela fez uma vira-volta grande. Ela está dona de si, é muito independente e superexigente, as coisas têm que ser como ela gosta" (M6; 18m); "Porque ela está fazendo isso para crescer. Porque ela chora, se atira no chão, faz birra, não quer isso, não quer aquilo" (M14; $19 \mathrm{~m})$.

Este movimento de independência também foi verificado quanto à alimentação, e muitas mães (13) referiram que o filho expressava preferências, recusando certos alimentos e aceitando outros: "Ele sabe mais o que quer. Recusa certos alimentos, escolhe o que quer" (M5; 18m); "Então ela está mostrando mais preferência pelo salgado do que pelo doce" (M14; 19m). Ainda na hora das refeições, duas mães disseram que os filhos começaram a comer sozinhos e a manipular os alimentos: "Começou a comer sozinho, é uma fase que tem que deixar, ele faz muita sujeira, joga, pega, essas coisas que criança faz mesmo" (M5; 18m); "Está um pouquinho bagunçada, porque ela quer comer sozinha. Aí às vezes come direito, às vezes não" (M6; 18m).

As preferências do filho também foram relatadas por várias mães (9) ao se referirem à resistência da criança a trocar de roupa, aliada às próprias escolhas sobre a roupa a ser vestida: "Hoje eu ia colocar outra roupa nela, mas ela enfiou na cabecinha dela, aquele sapato ali e a calça, quando viu que eu ia colocar outra, começou o berreiro, ela dizia 'não' e teve que vir com aquela ali" (M4; 19m); "Daí ela já está de roupa e quer vestir aquela roupa que ela quer" (M13; $21 \mathrm{~m})$. Estes movimentos de independência também foram associados por várias mães (8) à maior atividade da criança, na medida em que resistiam à troca de roupas e ficavam inquietas durante esse momento: "Quando ele vai botar a roupa, ele foge, não para quieto, fica alvoroçado, pula em cima da cama e quer correr pelado" (M5; 18m). Verificou-se também menção, por parte de quase todas as mães (12), aos movimentos de independência do filho na hora do banho, na medida em que tomavam iniciativas: "O que ele mais gosta é do banho: vai lá, pega a toalha, enrola e sai, vai para o banheiro e já quer tirar a roupa e quer tomar banho" (M8; $18 \mathrm{~m})$; 
"Ele se lava, quando eu vejo ele sumiu, está no box" (M10; 19m).

No que se refere aos sentimentos maternos ante as aquisições socioemocionais relacionadas à independência da criança, destaca-se que nenhuma mãe relatou sentimentos positivos. Apenas uma mãe indicou sentimentos negativos, não tendo paciência para as manifestações de birra de seu filho: "Nunca suportei criança que fizesse birra, sapateasse, chorasse, o tempo todo chorando, eu não tenho paciência para isso" (M12; 21m). Por outro lado, algumas mães (3) relataram sentimentos ambivalentes com relação à independência, por ser uma tarefa difícil para elas. Se, por um lado, as mães procuravam ensinar seus filhos a não serem mal-educados, por outro buscavam não ser muito exigentes: "Estou tentando ensinar as coisas certas para ela não ser uma criança mal-educada. Não quero ser uma mãe muito exigente. A gente começa a exigir muito, eu não queria ser assim. Inclusive eu tento maneirar, parar e pensar no que eu estou fazendo. Mas é dificil" (M12; $21 \mathrm{~m})$; "Eu queria que a gente tivesse uma relação boa, aberta, que ela se sentisse segura comigo, que a gente fosse sempre bem companheiras. Eu não queria que ela tivesse medo ou receio de fazer alguma coisa, de conversar comigo. Eu tento passar para ela que eu sou a mãe dela, mas que também sou amiga dela, que eи amo ela, que eu vou ajudar ela, que ela sempre pode contar comigo" (M12; 21m). Houve ainda referência de que, embora o crescimento e a independência da filha fossem algo bom, acabavam despertando receio sobre como ela seria depois que crescesse: "Quanto maior, a gente vai aprendendo mais. Já que a gente sente que quando eles crescem, eles voam. Eu adoro ver ela autônoma, dona do nariz dela, mas a gente quer ficar abraçando, porque depois eu não sei se eu vou abraçar, não se sabe como é que vai ser. Vou tentar que ela seja sempre apaixonada pela gente, mas vai depender dela" (M3; $19 \mathrm{~m})$.

Além disso, várias mães (6) indicaram que o filho demandava mais atenção na interação com os pais. Isto também pode ser visto como associado aos movimentos de independência da criança, na medida em que indica posicionamento: "Ele está tomando mais tempo. Se eu e o pai dele estamos conversando, ele está lá brincando, ele quer ficar junto, quer que a gente brinque com ele. Aí eu estou começando a mostrar para ele que é para ficar ali que eu e o pai estamos conversando" (M5, 18m); "Corre, fala. Se a gente não está olhando ele vai na frente, chama, quer mostrar e se fez alguma coisa que a gente mostra que gostou, ele faz de novo" (M5; 18m). Em contraposição, duas mães disseram que o filho mostrava-se ambivalente nos momentos de separação. Se, em um momento, a criança se separava da mãe sem dificuldade, em outro manifestava algum descontentamento: "Tem dias que ele fica numa boa [na escola], tem dias que ele quer vir comigo" (M7; $18 \mathrm{~m})$; "A gente nunca se escondeu para sair, sempre dava tchau, ontem que ela deu uma choramingada" (M14; 19m). Várias mães (6) destacaram também que o filho desejava permanecer próximo delas a maior parte do tempo, indicando movimentos de dependência: "O que ele mais gosta de fazer é estar comigo, é um grude" (M7; 18m); "Ele pega os brinquedos dele e senta no meu pé, está sempre cuidando o que estou fazendo" (M11; 18m). "Sempre, sempre [junto da mãe] parece uma sombra, onde eu estou tem que estar junto" (M12; 21m). Uma mãe destacou a dependência da filha na hora de dormir, uma vez que esta somente se deitava com a presença dela, a menos que estivesse com muito sono: "Ela só vai quando eu vou, se eu quero que ela vá dormir antes, tem que ir deitar, a não ser que esteja com muito sono" (M6; 18m).

Estes comportamentos de dependência da criança despertaram sentimentos negativos e ambivalentes nas mães, não sendo relatados sentimentos positivos. Cinco das mães destacaram o cansaço e estresse ante as demandas do filho. Uma mãe em particular referiu brigar com a filha por sentir-se cansada em função da demanda de proximidade física: "A gente briga muito, ela quer sempre estar em cima de mim, estar no meu colo, sempre colada. Eu digo: 'agora não dá. Estou cansada! Chega!' Mas, não adianta” (M3; 19m). Outra mãe também se sentia irritada e cansada quanto às manifestações de dependência da filha na hora de dormir: "Às vezes eu acordo e me irrito, ela começa a sapatear, chorar e tenta levantar, seguro ela na cama ela chora um pouquinho e dorme, agora tem vez que estou muito cansada, aí brigo mesmo pra ela dormir" (M12; 20m). Sentimentos negativos estiveram ainda associados às separações de uma das mães e sua filha: "Foi difícil, eu ficava com o coração esmagado. Eu estava na sala de aula e ficava pensando: 'Será que ela está bem, que está brincando, que não está chorando'?" (M12; 21m).

Diversos relatos de sentimentos maternos (6) ambivalentes apareceram com referência às aquisições socioemocionais do filho. Se, por um lado, essas demandas despertavam algo amoroso nas mães, por outro as faziam sentir-se presas, trancadas e incomodadas: "Isso de sentar em cima do meu pé, eu acho um amor, acho uma coisa carismática, mas às vezes me sinto presa, quero ir caminhar, fazer alguma 
coisa, e estou trancada, então me sinto meio amarrada, entre aspas, nesse aspecto. Eu acho que isso aí seria, de nós dois, o que mais me incomoda” (M11; 18m). Sentimentos maternos ambivalentes em face da aproximação e separação do filho também foram relatados por várias mães (7); ora houve sentimentos de falta nos momentos de separação, ora de cansaço nos de aproximação: "Senti falta dela. Ela preenche o dia e a noite, os segundos, cada dia ela apresenta uma novidade, que é um amor. Eu estou [querendo botar na escola] porque estou pretendendo trabalhar, ah, senão tu cansa! Me sinto muito sozinha, muito presa” (M13; 21m).

\section{Aquisições intelectual-cognitivas}

Esta categoria diz respeito às percepções e aos sentimentos maternos decorrentes das aquisições intelectual-cognitivas do filho. As falas das mães foram classificadas em termos de compreensão de regras, comportamentos de imitação e brincadeira simbólica do filho.

Várias mães (7) destacaram a maior habilidade e inteligência de seu filho: "Ela liga o rádio, se ela quer escutar rádio ela escuta, se ela quer escutar disco ela bota, o CD ela liga e desliga” (M4; 19m); "Acho que agora ela está crescendo melhor, está se desenvolvendo bem, ela é uma criança bem ativa, bem esperta, ela presta atenção no que a gente fala" (M12; 20m). Várias mães (8) também assinalaram a capacidade do filho para entender o que lhe estava sendo comunicado, em termos de compreensão de regras e conceitos: "Ela é uma criança boa de se lidar, de se explicar as coisas, de educar, de conversar principalmente, 'não vai, não mexe aî' ela é uma criança superboa de lidar nessa parte” (M13; 20m); "Eu digo para ele 'vamos papá', ele mostra a cadeira que tem que sentar, que eu tenho que pegar a toalha e botar ali, ele tem um senso" (M11; 18m).

Algumas mães (3) relataram que o filho entendia o que era dito, no entanto apresentava comportamentos de desafio diante destas regras: "Ele vê uma tomada, sabe que não pode, mas daí ele me chama para ver que ele está mexendo [na tomada]" (M10; 19m); "A gente fica falando e ele fica rindo, debochadinho, não leva a sério. E eu digo 'não, não' e ele rindo. Daí como a gente já está cansada, acabo gritando, ele chora e daí me derruba" (M10;19m).

Várias mães (8) também relataram comportamentos de imitação de adultos e de animais neste período do desenvolvimento: "Eu estou na pia lavando louça, ela já pega um paninho e quer fazer a mesma coisa" (M4; 19m); "Eu estou fazendo os meus trabalhos, então ela quer fazer igualzinho. Daí ela pega uma folha e fica, e olha o que eu estou fazendo $e$ depois acha que está fazendo a mesma coisa" (M12; $21 \mathrm{~m})$; "Ele imita, cuida uma pessoa e a gente diz: 'imita'. Ele imita o cachorro, o patinho da avó" (M10; 19m). Houve também por parte de uma mãe associação entre estes comportamentos de imitação e mudanças nos tipos de brincadeira: "Tem brincado bastante de limpar as coisas, pega o paninho e passa e limpa, os brinquedinho dele. Já está mudando um pouco, não está tão como ele era antes, está mudando a maneira de brinquedo dele” (M11; 18m).

Além das brincadeiras próprias dessa faixa etária, a maioria das mães (10) relatou aquisição de brincadeiras simbólicas: "Ela faz bombinha no nenê. Eu faço os medicamentos nela, aí ela faz direitinho nos nenês dela. Eu dei uma embalagem vazia, daí ela faz com a garrafinha. Isso aí me chamou atenção. Ela troca as fraldas do nenê dela, pega o bico, tudo o que eu faço nela ela quer fazer" (M1; 18m); “As bonecas ela brinca muito, nana e enrola e dá bico, bota no seio" (M6; 18m); "Ele brinca, bota aparelhinho no carrinho, estaciona, tira da garagem" (M8; $18 \mathrm{~m})$.

Diante das aquisições intelectual-cognitivas, foram relatados tanto sentimentos positivos quanto negativos e ambivalentes. Algumas mães (3) relataram alegria, realização, superação de expectativas e surpresa em relação a estas novas habilidades: "Eu me sinto realizada. Acho que na realidade era mais do que eu pensava. Ela é tão esperta, tudo que eu falo para ela, ela entende, aprende as coisas com facilidade. Eu não achei que eu ia ter uma filha assim" (M12; 21m); "Eu fico contente que ela é uma criança assim, e as pessoas falam para mim: 'Como ela é inteligente, nunca vi uma criança assim!” (M4; $19 \mathrm{~m})$; "Ela é tri-inteligente. Ela conta realmente até dez, está olhando ali, ela está falando o que está olhando como se estivesse lendo, no meu modo de ver" (M13; 20m). Duas mães também relataram sentimentos positivos em relação às brincadeiras com o filho, na medida em que apreciaram participar desses momentos: "Ela repete bastante o que acontece na creche com as bonecas, como é que a gente faz ela dormir, é bem engraçado isso" (M9, 18m); "Ah, eu gosto! Eu adoro [brincar com ele]” (M5; 18m). Com relação aos sentimentos negativos, uma mãe relatou não ter paciência para as demandas de brincadeiras do filho: "Convida, eu, quando faço 'atirei o pau no gato' com ele, aí ele quer ficar o tempo todo ali no 'atirei o pau no gato', aí eu não tenho paciência, 'deu, chega filho"' (M7; 18m). Por fim, algumas mães (3) relataram sentimentos ambivalentes quanto aos pedidos de que a mãe brincasse. Se, por um lado, os relatos indicaram ausência de paciência, por outro, 
apontaram sentimentos maternos de culpa por não ter mais disponibilidade para o filho na hora de suas brincadeiras: "A maior parte do tempo eu passo brincando, porque ela vem sempre me chamar para brincar. Às vezes tu está disposta, às vezes tu tem outras coisas para fazer então não pode ficar. Mas a maioria das vezes é bem legal brincar com ela. Eu largo as coisas que eu tenho para fazer e fico brincando com ela" (M9; 18m); "Acho que eu era bem mais calma com ele, de vez em quando eu perco a calma, depois me culpo, me acho a pior criatura. Quando ele pula, às vezes nem está fazendo nada, parece que é mais. E como ele é mais fraco, quando está ao redor, acabo descontando nele, qualquer coisinha que faça, às vezes estou cansada. Fica tudo bagunçado, acabo ficando irritada e depois no mesmo instante já estou arrependida de tudo. Então acho que tinha que estar mais calma, que estou muito estressada" (M10; 19m); "[Ao brigar] me sinto "tri mal'. Eu sinto, puxa vida, não volto atrás, mas explico para ela por que agi daquela forma. Não sei, acho que eu ainda tenho muito que aprender" (M12; 21m). Uma das mães percebia que a filha insistia para brincar e a incentivava para cativá-la: "Conversa, caminha, leva muito os brinquedos para brincar junto, mas às vezes ela te obriga a sentar e brincar. E ela incentiva muito. Aí tu fica mais voltada a dar atenção pra ela" (M19; 18m).

\section{DISCUSSÃO}

Os resultados do presente estudo apontaram que as aquisições de linguagem e intelectual-cognitivas favoreceram a comunicação e entendimento entre mãe e criança no período dos 18 aos 20 meses. Tanto em relação às aquisições socioemocionais quanto às motoras, destacaram-se movimentos de independência, indicados através de preferências, expressões de sentimentos e opiniões próprias, além da maior demanda de atenção e proximidade materna, que remeteu à dependência, despertando nas mães sentimentos positivos, negativos e ambivalentes.

Quanto à linguagem, os relatos maternos indicam que as crianças apresentaram diversas aquisições no que se refere à habilidade de comunicação e expressão. Essa nova habilidade infantil suscitou sentimentos maternos positivos, denotando a importância atribuída à aquisição de linguagem como forma de favorecer a compreensão materna, já que repercutiu na interação e no relacionamento mãecriança. Em comparação com o que foi descrito por Lopes et al. (2007), que investigaram as crianças aos
12 meses, no presente estudo pôde-se constatar um aumento expressivo de relatos que destacaram a importância da linguagem cada vez mais elaborada das crianças no final do segundo ano de vida.

Assim, os relatos deste estudo corroboram as ideias de outros autores (Kedar, Casasola \& Lust, 2006; Steiner, 1999), os quais apontam a aquisição da linguagem verbal como um importante evento do desenvolvimento infantil, que vai se complexificando (Colson \& Dworkin, 1997; Piccinini, Alvarenga, Frizzo, Lopes, \& Tudge, 2007), especialmente no final segundo ano de vida. Esta aquisição tornou as crianças do presente estudo capazes de expressar o que precisavam através de palavras, o que antes era mais realizado através de sinais e gestos. Esta maior habilidade comunicativa possibilitou à criança expressar verbalmente seus sentimentos de forma mais compreensível (Shaffer, 2005). Tal capacidade gerou sentimentos de admiração e satisfação nas mães, que costumavam apreciar o uso de palavras pelos filhos, o que os possibilitava ir além da comunicação nãoverbal. Esta melhor compreensão da fala ajuda a criança a nomear objetos e a criar um senso de continuidade na vida cotidiana (Steiner, 1999), permitindo, além da imitação, a descrição de situações de seu ambiente.

Os relatos das mães referentes às aquisições motoras revelaram uma maior atividade $\mathrm{e}$ independência física por parte da criança, que passou a apresentar mais agilidade, segurança e capacidade para explorar o ambiente. Isto se constitui em um importante avanço com relação às aquisições motoras descritas por Lopes et al. (2007), em que as mães de crianças de 12 meses destacavam o comportamento exploratório, associado à motricidade ampla. Dos 18 aos 20 meses, as aquisições de motricidade fina e a maior agilidade possibilitaram à criança mais segurança e capacidade para realizar movimentos de independência.

Não obstante, as novas demandas de cuidado e tempo por parte de uma criança mais exploradora e independente acabaram repercutindo nos sentimentos de algumas mães, particularmente as que trabalhavam fora de casa. Nesta situação, predominaram sentimentos negativos e ambivalentes, particularmente no que se refere à motricidade, apesar de as mães saberem da importância destas novas aquisições. É possível também que isto esteja ligado ao sentimento de ameaça de perda da dependência do filho, enquanto este se encontra no processo de adquirir independência (Winnicott, 1979/1983). A mãe podia estar entendendo as vantagens desse momento, mas 
não estar conseguindo a necessária liberação de seus sentimentos (Winnicott, 1979/1983).

No tocante às aquisições motoras, as mães tenderam a não relatar sentimentos positivos frente à habilidade de caminhar adquirida pelas crianças. Essa importante aquisição pode representar a longa jornada a ser percorrida pela criança em seu crescimento e suas repercussões nos sentimentos maternos. Além do impacto do caminhar no desenvolvimento psicológico e físico (Steiner, 1999), destaca-se a multiplicidade de sentimentos gerados na mãe em decorrência de seu filho poder se afastar e se reaproximar, independentemente do desejo materno. Esta passagem de "bebê de colo" para a criança que já pode separarse fisicamente da mãe marca um importante passo evolutivo na maternidade, fazendo com que tanto a criança quanto a mãe vivenciem um processo de separação (Mahler, 1982). Ao afastar-se e retornar à mãe, o bebê também vivencia sentimentos tanto de prazer quanto de ansiedade (Mahler, 1982). O início dessa caminhada pode ser uma experiência repleta de surpresas e dúvidas, tanto para a mãe como para a criança.

Já com relação às aquisições socioemocionais, os relatos maternos apontaram para comportamentos que remeteram tanto a maior independência quanto a comportamentos de dependência da criança, despertando sentimentos maternos negativos e ambivalentes diante destas manifestações. Não houve referência a sentimentos positivos nessa categoria. Através dos relatos maternos, percebeu-se também que as crianças puderam expressar seus sentimentos e interagir com a mãe, além de explorar objetos e expressar-se através de brincadeiras simbólicas (Feldman, Eidelman, \& Rotenberg, 2004; Mendes \& Moura, 2004). As brincadeiras possibilitam à criança lidar com as emoções e oportunizam novos meios de interação (Steiner, 1999; Trevarthen, 2005).

Os resultados também mostram que as mães compreendiam a importância dos movimentos de independência nesse momento do desenvolvimento. $\mathrm{O}$ afastamento e a reaproximação do filho em relação à mãe foram conceituados por Mahler (1982) como crise de reaproximação. Estes comportamentos contribuem para reassegurar os sentimentos de proximidade e amor da díade. Nesse período, é usual que a criança corra e faça com que a mãe tenha que ir atrás dela. Desta forma, estaria se certificando de que a mãe está atenta a seus movimentos, mas que também tolera e aceita suas tentativas de independência (Lovas, 2005; Piccinini et al., 2007; Steiner, 1999). Isso exige uma boa dose de flexibilidade da mãe, que tem de se adaptar aos sentimentos despertados por estas novas atitudes e, ao mesmo tempo, incentivar as explorações. Mediante esse cuidado para com o filho a mãe expressa seus sentimentos e seu interesse.

Com relação à dependência, os relatos das mães indicaram que os filhos pareciam demandar mais, exigir maior atenção nos momentos de interação, além de expressar desejo de permanecer próximos a elas. Estes comportamentos de dependência despertaram sentimentos negativos e ambivalentes. Os sentimentos negativos incluíram cansaço e irritação pela demanda de proximidade física; os sentimentos ambivalentes foram percebidos em termos de demandas de atenção. $\mathrm{Se}$, por um lado, essas demandas despertavam algo amoroso, por outro, faziam-nas sentir-se presas, trancadas, amarradas e incomodadas com tal fato. Isso corrobora as ideias de Newcombe (1999), segundo as quis os pais não podem simplesmente esperar que os filhos amadureçam, mas precisam cuidá-los diariamente, de forma a protegê-los. As mães do presente estudo também encontraram uma forma de não interferir na autonomia, ao mesmo tempo em que favoreceram a expressão de movimentos de independência de seus filhos. A aptidão da criança para separar-se da mãe (Mahler, 1982; Pine, 2004) é destacada na liteturatura referente a esse período do desenvolvimento, representada pelos movimentos de independência da criança (Miller, 1999); porém os aspectos da dependência também acompanham esses ensaios de busca de autonomia feitos pela criança, quando esta se depara com suas limitações. Assim, tanto a mãe como a criança podem apresentar comportamentos ambivalentes quanto à aquisição de independência e às frequentes separações cotidianas. A maneira de enfrentar esse período também pode repercutir em momentos posteriores em que a díade tenha que lidar com novas separações.

Por fim, quanto às aquisições intelectualcognitivas, os relatos maternos apontaram maior habilidade, inteligência e capacidade na compreensão de regras e conceitos da criança, além de comportamento desafiador diante destas regras. As aquisições intelectual-cognitivas constituem-se em um importante avanço em termos de desenvolvimento, e também são bastante visíveis no final do segundo ano de vida (Newcombe, 1999). As brincadeiras de imitação, já descritas por Lopes et al. (2007), e na literatura (Trevarthen, 2005), foram aqui somadas às brincadeiras simbólicas, possibilitando à criança maior destreza intelectual e cognitiva. O crescimento da capacidade simbólica é um passo importante, uma vez que as mães percebem que seus filhos estão amadurecendo e adquirindo habilidades. 
As mães relataram sentimentos positivos, negativos e ambivalentes quanto às aquisições intelectual-cognitivas. Os primeiros estiveram relacionados a alegria, realização, superação de expectativas e surpresa. Por outro lado, tanto os relatos de sentimentos negativos quanto os de sentimentos ambivalentes remeteram à falta de paciência diante das demandas do filho, especialmente em momentos de brincadeira em que a exigência de disponibilidade era maior.

De maneira geral, os resultados do presente estudo mostram ter havido incremento de aquisições de vocalizações para a fala, de motricidade ampla para fina, de imitação para brinquedo simbólico, quando comparado com estudo anterior de Lopes et al. (2007), realizado com 28 crianças de 12 meses de idade. Apontam ainda que os sentimentos positivos estiveram mais associados às aquisições de linguagem e intelectual-cognitivas, enquanto os negativos e ambivalentes estiveram associados às aquisições motoras e socioemocionais.

Dada a importância desse período do desenvolvimento infantil, torna-se relevante que as mães compreendam o significado das aquisições próprias desta fase e ofereçam ao filho oportunidades para afastamentos e reaproximações, atentando para os seus sentimentos decorrentes destes movimentos. Ao entender essa oscilação da criança, a mãe pode lidar com a mudança de uma relação de dependência e se adaptar à busca de independência do filho. Destarte, ao mesmo tempo em que desejam ver o desenvolvimento dos filhos, algumas mães parecem temer o inevitável afastamento trazido pelo crescimento.

\section{REFERÊNCIAS}

Bardin, L. (1977). Análise de Conteúdo (L. A. Reto, \& A. Pinheiro, Trad.). Lisboa: Edições 70.

Brazelton, T. B. (2002). Momentos decisivos do desenvolvimento infantil (J. L. Camargo, Trad.). $2^{\text {a }}$ ed. São Paulo: Martins Fontes.

Colson, E. R., \& Dworkin, P.H. (1997). Toddler Development. Pediatrics in Review, 18(8), 255-259.

Feldman, R., Eidelman, A. I., \& Rotenberg, N. (2004). Parenting stress, infant emotion regulation, maternal sensitivity, and the cognitive development of triplets: A model for parent and child influences in a unique ecology. Child Development, 75, 1774 1791.

Grupo de Interação Social, Desenvolvimento e Psicopatologia GIDEP/UFRGS/CNPq (1998). Entrevista sobre a Experiência da Maternidade e o Desenvolvimento da do Bebê aos 18 meses. Instrumento não-publicado. Instituto de Psicologia. UFRGS.
Grupo de Interação Social, Desenvolvimento e Psicopatologia GIDEP/UFRGS/CNPq (1998). Ficha de Contato Inicial. Instrumento não-publicado. Instituto de Psicologia. UFRGS.

Grupo de Interação Social, Desenvolvimento e Psicopatologia GIDEP/UFRGS/CNPq (1998). Entrevista de Dados Demográficos. Instrumento não-publicado. Instituto de Psicologia UFRGS.

Hollingshead, A. (1975). The four-factor index of social status. Yale University. Manuscrito não-publicado.

Kedar, Y., Casasola, M., \& Lust, B. (2006). Getting There Faster: 18and 24-Month-Old Infants' Use of Function Words to Determine Reference. Child Development, 77(2), 325-338.

Laville, C., \& Dionne, J. (1999). A construção do saber: manual de metodologia de pesquisa em ciências humanas. Porto Alegre: Artes Médicas.

Lopes, R. de. C. S., Oliveira, D. S. de, Vivian, A. G., Bomhgarehn, L. M. C., Piccinini, C., \& Tudge, J. (2007). Sentimentos maternos frente ao desenvolvimento da criança aos 12 meses: Convivendo com as novas aquisições infantis. Psicologia: Teoria e Pesquisa, 23(1), 5-15.

Lovas, G. S. (2005). Gender and patterns of emotional availability in mother-toddler and father-toddler dyads. Infant Mental Health, 26(4), 327-353

Mahler, M. (1982). O processo de separação-individuação. (H. M. de Souza, Trad.). Porto Alegre: Artes Médicas (Original publicado em 1979).

Mendes, D. M. L. F., \& Moura, M. L. S. de (2004). Desenvolvimento da Brincadeira e Linguagem em Bebês de 20 Meses. Psicologia: Teoria e Pesquisa, 20(3), 215-222.

Miller, L. (1999). Babyhood: Becoming a person in the family. In D. Hindle \& M. Vaciago Smith. Personality development: a psychoanalytic perspective (pp. 33- 47). London: Routledge.

Moura, M. L. S. de \& Ribas, A. F. P. (2002) Imitação e desenvolvimento inicial: evidências empíricas, explicações e implicações teóricas. Estudos em Psicologia (Natal), 7(2), 207215.

Newcombe, N. (1999). Desenvolvimento infantil: abordagem de Mussen (C. Buchweitz, Trad.). $8^{\text {a }}$ ed. Porto Alegre: Artes Médicas.

Papalia, D. E., Olds, S. W., \& Feldman, R. D. (2006). Desenvolvimento humano (D. Bueno, Trad.). $8^{\mathrm{a}}$ ed. Porto Alegre: Artes Médicas.

Piccinini, C., Frizzo, G. B., Alvarenga, P., Lopes, R. C. S., \& Tudge, J. (2007). Práticas educativas de pais e mães de crianças aos 18 meses de idade. Psicologia: Teoria e Pesquisa, 23(4), 369-377.

Piccinini, C., Tudge, J., Lopes, R. C. S., \& Sperb, T. (1998). Estudo longitudinal de Porto Alegre: da gestação à escola. Instituto de Psicologia, UFRGS, Projeto não publicado.

Pine, F. (2004). Mahler's concepts of "symbiosis" and separationindividuation: revisited, reevaluated, refined. Journal of the American Psychoanalytic Association, 52(2), 511-533.

Shaffer, D. R. (2005). Psicologia do Desenvolvimento: Infância e Adolescência (C. R. P. Cancissu, Trad.). São Paulo: Thomson.

Sohr-Preston, S. L., \& Scaramella, L. V. (2006). Implications of Timing of Maternal Depressive Symptoms for Early Cognitive and Language Development. Clinical Child and Family Psychology Review, 9(1) 65-83. 
Thompson, R. A., \& Lagattuta, K. H. (2005). Feeling and understanding: Early emotional development. In K. McCartney \& D. Phillips (Eds.) The Blackwell Handbook of Early Childhood Development (pp. 317-337). Blackwell Publishing. Online retirado em 23 de abril de 2009 http://www.blackwellreference.com/public/book?id=g978140512 0739_9781405120739

Trevarthen, C. (2005). First things first: infants make good use of the sympathetic rhythm of imitation, without reason or language. Journal of Child Psychotherapy, 13(1), 91-113.

Steiner, D. (1999). The toddler and the wider world. In D. Hindle \& M. V. Smith. Personality development: a psychoanalytic perspective (pp. 48-62). London: Routledge.
Hodges, J., \& Klee, T. (2005). Quantity and quality of parental language input to late-talking toddlers during play. Child Language Teaching and Therapy, 21(2), 107-122.

Winnicott, D. W. (1983). O ambiente e os processos de maturação. (I. C. S. Ortiz, Trad.). Porto Alegre: Artes Médicas. (Trabalho original publicado em 1979).

Recebido em 31/07/2007 Aceito em 11/08/2008

Endereço para correspondência :

Rita de Cássia Sobreira Lopes. Instituto de Psicologia, Universidade Federal do Rio grande do Sul. Rua Ramiro Barcelo, 2600, sala 108, CEP 90035-003, Porto Alegre-RS, Brasil. E-mail: sobreiralopes@portoweb.com.br 